\title{
Uncovering Novel Peptide Chemistry from Bacterial Natural Products
}

\author{
Florian Hubrich ${ }^{\S}$, Alessandro Lotti§, Thomas A. Scott ${ }^{\S}$, and Jörn Piel ${ }^{\star}$
}

\begin{abstract}
Nature has evolved a remarkable array of biosynthetic enzymes that install diverse chemistries into natural products (NPs), bestowing them with a range of important biological properties that are of considerable therapeutic value. This is epitomized by the ribosomally synthesized and post-translationally modified peptides (RiPPs), a class of peptide natural products that undergo extensive post-translational modifications to produce structurally diverse bioactive peptides. In this review, we provide an overview of our research into the proteusin RiPP family, describing characterized members and the maturation enzymes responsible for their unique chemical structures and biological activities. The diverse enzymology identified in the first two proteusin pathways highlights the enormous potential of the RiPP class for new lead structures and novel pharmacophore-installing maturases as biocatalytic tools for drug discovery efforts.
\end{abstract}

Keywords: Bacterial natural products · Biosynthetic gene clusters · Post-translational modifications · Proteusins $\cdot$ RiPPs

\section{Introduction}

Peptides represent an important source of novel therapeutics, with more than 80 peptide drugs now available on the global market for the treatment of a wide range of diseases including cancer, AIDS, diabetes, and multiple sclerosis. ${ }^{[1]}$ Peptides are often structurally more complex than other small molecule-based pharmaceuticals, which together with their protein-like structural features contribute significantly to potency and selectivity. ${ }^{[1,2]}$ Peptides are also more readily biodegraded, which limits their persistence in the environment. Despite frequent limitations in terms of low oral bioavailability and poor plasma stability, efforts to develop and improve peptide therapeutics continue, with over 150 peptides currently in clinical development and 400-600 undergoing preclinical trials. ${ }^{[1,2]}$

Historically, natural products (NP) have been a primary source of lead structures for drug discovery and development. ${ }^{[3]}$ Their success derives from the fact that they are the outcome of many rounds of natural selection for biosynthetic pathways that produce molecules interacting with specific, biologically relevant targets. Primary examples of NP-derived peptide drugs include the antibiotic of last resort daptomycin, the antitumor agent bleomycin, and the immunosuppressant cyclosporine. All three are assembled by non-ribosomal peptide synthetases (NRPSs), multi-domain mega enzymes that, in addition to the 20 canonical $\alpha$-amino acids, are able to incorporate nonproteinogenic amino acid and hydroxy acid residues into their bioactive peptide products. ${ }^{[4]}$

Another prominent NP peptide that has been on the market for several decades is the antibacterial food preservative nisin, which was first described in 1928 and features several characteristic cyclic thioether linkages called (methyl)lanthionines, formed between cysteine and either dehydroalanine (for lanthionine) or dehydrobutyrine (for 3-methyl lanthionine). Antibacterial peptides comprising such thioether bonds were consequently referred to as lantibiotics and were initially also believed to be produced via a non-ribosomal mechanism given these nonproteinogenic structural features ${ }^{[5]}$ However, inhibition of nisin synthesis by the ribo- some inhibitor chloramphenicol, and the subsequent sequencing of the biosynthetic genes for the lantibiotic epidermin in 1988, revealed the ribosomal origin of these antibacterial peptides. ${ }^{[6]}$ Lantibiotics are now known to belong to a rapidly expanding NP peptide class - the ribosomally synthesized and post-translationally modified peptides (RiPPs). ${ }^{77]}$

RiPPs are characterized by a common biosynthetic logic that begins with the ribosomal synthesis of a short (20-120 amino acids), gene-encoded precursor peptide (Fig. 1), often consisting of an N-terminal 'leader' region and a $C$-terminal 'core' region, although $\mathrm{N}$-terminal or mid-section cores are also known. ${ }^{[7]}$ The leader serves as a recognition and/or self-resistance element for various post-translational modification (PTM) enzymes, also termed maturases. These install diverse chemical functionalities in the core peptide region that bestow important biological properties on the resulting peptide product (e.g. stability or bioactivity). Subsequent proteolytic cleavage by one or more dedicated proteases results in release of the final mature peptide from the leader sequence, a process that is also often coupled with the active export of the bioactive peptide from the cell.

In addition to providing a rich source of novel chemical scaffolds, RiPP PTM enzymes also represent attractive tools for synthetic biology applications. The physical separation of substrate recognition from catalysis often means that PTM enzymes display a high degree of substrate tolerance with respect to precursor core sequences. ${ }^{[7,8]}$ This feature, in addition to the gene-encoded nature of precursor peptides, permits the rapid generation and screening of large modified peptide libraries for desirable bioactivities, whilst simultaneously overcoming many of the restrictions imposed by chemical synthesis routes (limited building blocks, harsh reaction conditions, etc.).

The short nature of precursor encoding genes, in combination with the lack of other common genetic markers make identifying RiPP pathways particularly challenging and explain why the true diversity of this NP superfamily remained enigmatic for so many years. However, with advances in genome sequencing ca- 


\section{RiPP biosynthetic gene cluster}
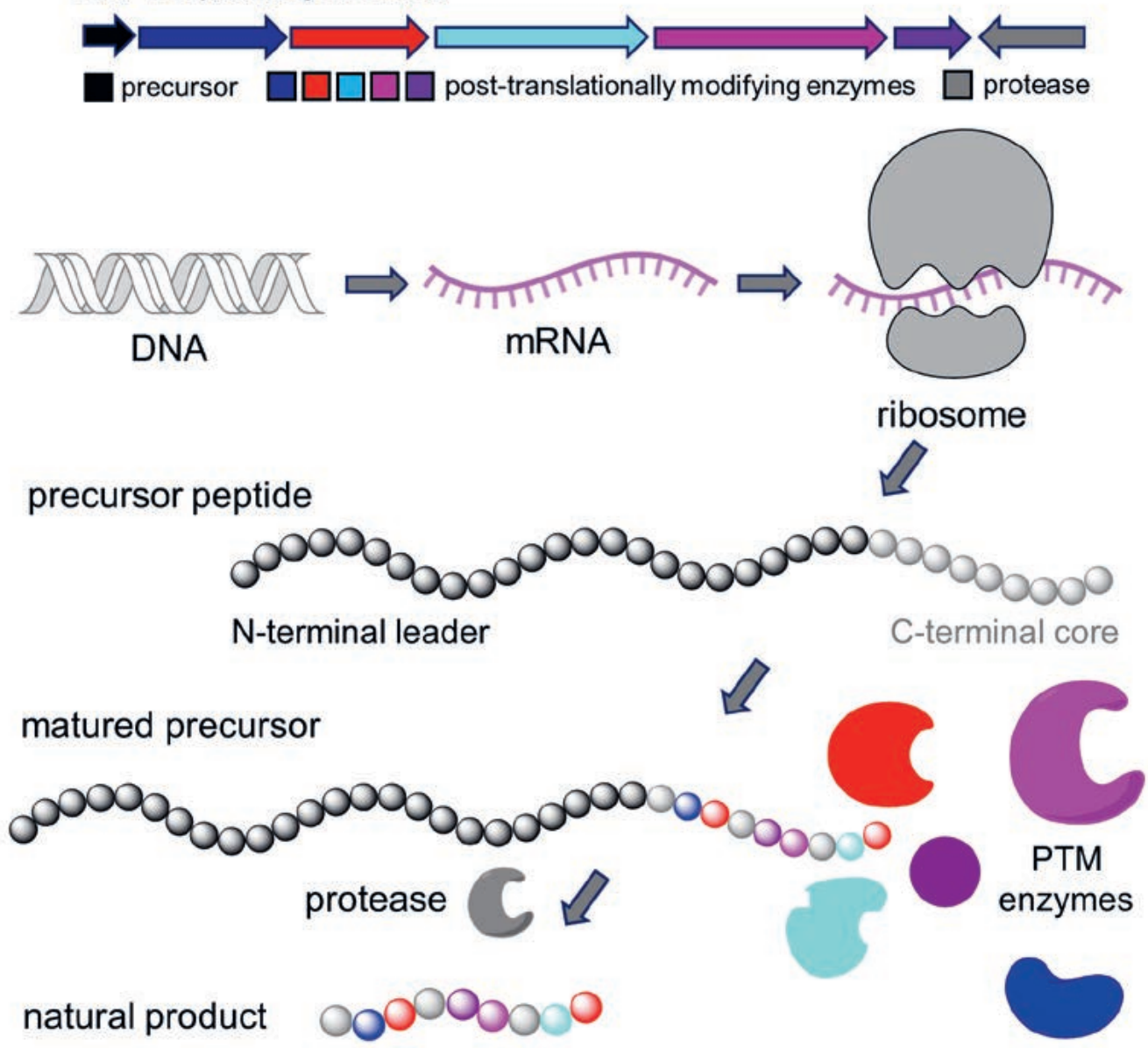

Fig. 1. Overview about the general biosynthetic logic of ribosomally synthesized and posttranslationally modified peptides (RiPPs). A typical RiPP biosynthetic gene cluster (BGC) consisting of one or several genes encoding for precursor peptides (black arrow), post-translationally modifying (PTM) enzymes (colored arrows) and a protease (grey arrow). The precursor gene encoded in the RiPP BGC is transcribed into mRNA and subsequent ribosomally translated into a precursor peptide. This precursor peptide consists of a N-terminal leader (black bubbles) and a C-terminal core region (light grey bubbles). The $\mathrm{N}$-terminal leader serves as a recognition element for the modifying enzymes (colored) that install post-translational modifications in the core region (colored bubbles) leading to a matured precursor peptide. Finally, the protease cleaves off the leader region from the matured core leading to the final natural product. pacities in the $21^{\text {st }}$ century and the development of tools for the identification of these pathways, the RiPP class has seen a significant expansion that has unveiled a remarkable diversity of novel PTMs. ${ }^{[8]}$ In this review, we describe our lab's own investigations on the proteusins, a largely unexplored RiPP family that harbors enormous potential for the discovery of novel peptide chemistry.

\section{Polytheonamides - The First Proteusins}

Our lab's interest in RiPP biosynthesis stems from studies into marine sponges, which are known to contain a wealth of structurally distinct specialized metabolites. ${ }^{[9]}$ Our research was initially centered on Theonella swinhoei, a sponge harboring diverse and unique chemical compounds. Using metagenomic and singlecell approaches, it was revealed that the majority of the chemical repertoire from this sponge is actually produced by chemically prolific bacterial symbionts belonging to the uncultivated candidate genus 'Entotheonella'. ${ }^{[10]}$ The largest and most structurally complex of these metabolites are the polytheonamides (Fig. 2A), 49 mer linear $\beta$-helical peptides featuring a plethora of nonproteinogenic residues with low-picomolar cytotoxic activity against mammalian cell lines. ${ }^{[10,11]}$ Given their unique chemical composition, it had therefore been previously assumed that the polytheonamides were the products of a large NRPS. However, discovery of the biosynthetic gene cluster (poy BGC) for polytheonamide production revealed that these remarkable peptides were ribosomally synthesized, and the founding members of a new RiPP family, the proteusins.

Unlike other RiPP families, the proteusins are not defined by any family-specific PTMs, but instead are distinguished by a common precursor architecture featuring a leader peptide with homology to nitrile hydratase proteins. ${ }^{[7,8]}$ Proteusin BGCs encode highly variable complements of PTM enzymes and likely repre- sent one of the most biosynthetically diverse known RiPP families. For example, our research showed that the polytheonamides are formed by action of seven PTM enzymes responsible for a remarkable cascade of $\sim 50$ PTMs that are central to the $\beta$-helical structure and resulting cytotoxicity of these peptide NPs. ${ }^{[11,12]}$

Through heterologous expression experiments, we have been able to functionally characterize all enzymes involved in polytheonamide maturation (Fig. 2A). PoyD, for example, is the founding member of a new family of radical $S$-adenosyl methionine (rSAM) epimerases that introduces $18 \mathrm{D}$-amino acid residues through irreversible L-to-D epimerization, resulting in an alternating D/L pattern. ${ }^{[12]}$ Not only do D-amino residues improve the stability of peptides by providing protection against proteolysis, but they can also drastically alter the structure and bioactivity of peptides, as is the case for the cytotoxic polytheonamide nanotubes. Epimerase activity could also be reconstituted in vitro, permitting the characterization of a mechanism mediated via $\alpha$-hydrogen abstraction of modified residues. ${ }^{[13]}$ Using a bespoke orthogonal $\mathrm{D}_{2} \mathrm{O}$-based induction system (ODIS), ${ }^{[14]}$ the substrate tolerance of PoyD and several of its orthologs identified from orphan cyanobacterial BGCs could also be examined using point mutants and truncated substrate peptide variants, in addition to core-swapping experiments. ${ }^{[15]}$ Proteusin epimerases displayed astonishing substrate promiscuity regarding epimerized amino acid residues and accepted core sequences. ${ }^{[15,16]}$ Orthologs also produced similar epimerization patterns when supplied with the same substrate, highlighting stringent regioselectivity for these enzymes and suggesting that epimerization patterns are dictated, to an extent, by the core peptide sequence. The cyanobacterial epimerase homolog OspD (see below) was even capable of modifying nonnative peptide sequences from medically relevant targets including glucagon, GnRH, human amyloid $\beta$-peptide and protegrin-1 
A
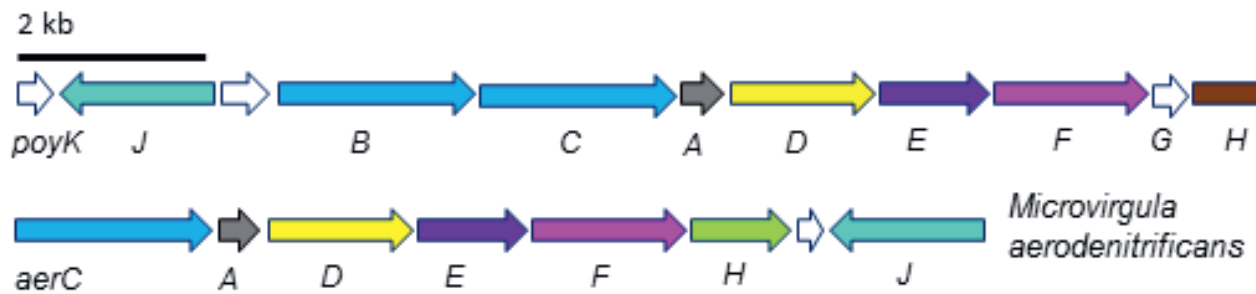

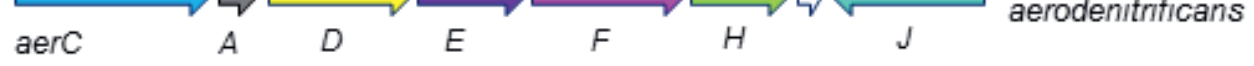

$\square$ rSAM C-methyltransferase $\square$ precursor $\square$ rSAM epimerase $\square$ N-methyltransferase $\square$ dehydratase

cysteine protease $\square$ serine protease $\square$ hydrolase $\square$ other $\square$ hydroxylase

Polytheonide A

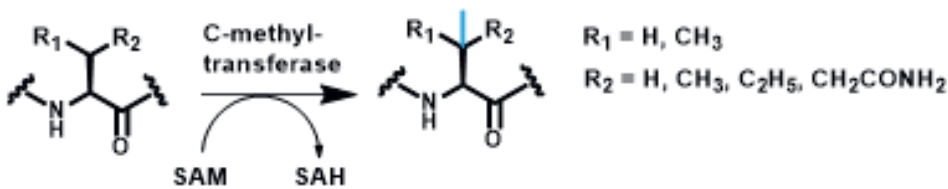

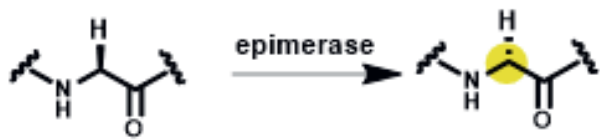

B

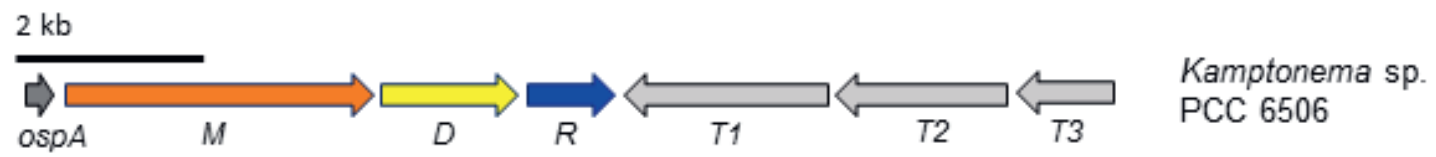

$\square$ precursor $\square$ type II lanthionine synthetase $\square$ rSAM epimerase $\square$ arginase $\square$ transporter

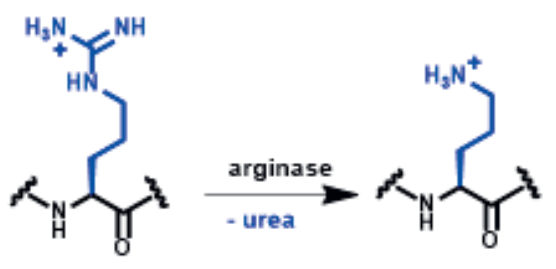

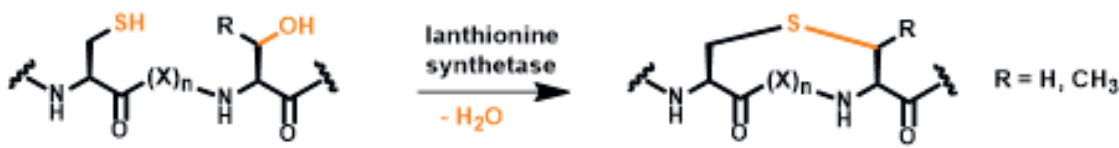

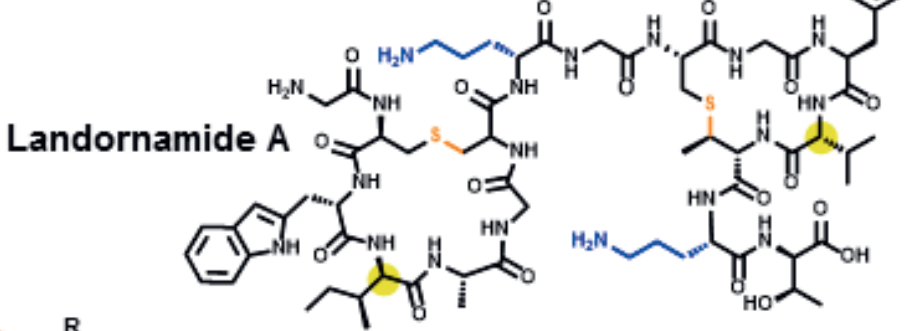

C

$2 \mathrm{~kb}$

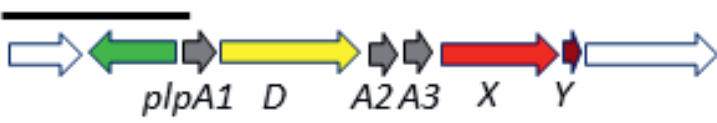

Pleurocapsa sp

PCC 7319

$\square$ rSAM epimerase $\square$ rSAM splicease $\square$ precursor

$\square$ putative hydroxylase

$\square$ other

rSAM splicease accessory protein

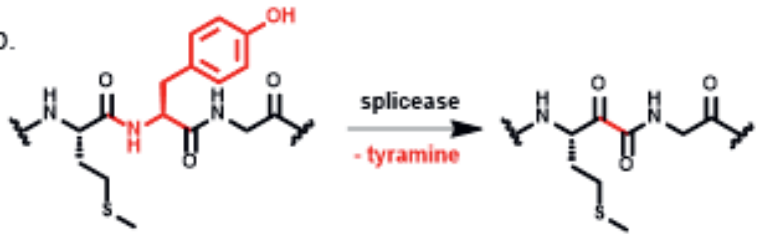

Fig. 2. Overview of proteusins and spliceotides previously studied in the Piel lab. The figure shows biosynthetic gene clusters (BCGs), characterized natural products (NPS) and key chemical reactions of the respective RiPP pathways. Conserved genes of BGCs and post-translational modifications in the NPs, as well as the corresponding chemical reactions are color-coded equally to highlight their distribution. Yellow dots in the chemical structures denote D-residues. A) Polytheonamide-type proteusin BGCs including the poy BGC from 'Enthoteonella factor' and the aer BGC from Microvirgula aerodenitrificans. The structure of polytheonamide $\mathrm{A}$ and the maturase reactions catalyzed by rSAM $C$-methyltransferases and epimerases are also shown. B) The osp proteusin BGC from Kamptonema sp. PCC 6506, the structure of the biosynthetic product landornamide A, and the maturase reactions catalyzed by lanthionine synthetases and arginases. C) The spliceotide-family p/p BGC from Pleurocapsa sp. PCC 7319 and the tyramine excision catalyzed by rSAM spliceases. 
when fused to its cognate substrate leader sequence. ${ }^{[16]}$ Proteusin epimerases therefore possess remarkable potential as synthetic tools for introducing peptide-stabilizing residues into therapeutic peptides.

Another iterative enzyme, the SAM-dependent methyltransferase PoyE, installs eight $N$-methylated Asn residues in the polytheonamide core in a distinctive $\mathrm{NX}_{5} \mathrm{~N}$ pattern. ${ }^{[12]}$ Given that six amino acids constitute one turn of the helix, the $\mathrm{NX}_{5} \mathrm{~N}$ motif repeats serve to align $\mathrm{N}$-methylated residues on the polytheonamide nanotube. The significance of this arrangement to the final product $\beta$-helical structure was confirmed by molecular dynamics calculations performed on polytheonamide variants, which highlighted the crucial contributions of PoyE-installed $\mathrm{N}$-methylated Asn residues and PoyD-epimerized residues to nanotube structure and stability by creating hydrogen bond clamps along the helix. ${ }^{[17]}$

Additional methyl groups are introduced by two cobalamindependent rSAM $C$-methyltransferases, PoyB/C, which are responsible for the catalysis of $17 C$-methylations of non-activated $s p^{3}$-carbon centers along the polytheonamide core. ${ }^{[12]}$ PoyC also catalyzes four methylations of an $\mathrm{N}$-terminal $\mathrm{Thr}$ residue, concomitant with dehydration of this residue by PoyF, resulting in an unusual tert-butyl group. This $\mathrm{N}$-terminal functionality also plays a key role in improving membrane insertion and the pore-forming activity of the polytheonamides.[12,18] Additionally, hydrophobic residues as represented by such $C$-methyl groups have been shown to enhance the membrane penetration capability of polytheonamide and strongly contribute to its cytotoxicity. ${ }^{[18]}$

By bioinformatically searching for co-occurrence of genes encoding a proteusin epimerase, $N$-methyltransferase, and a precursor containing $\mathrm{NX}_{5} \mathrm{~N}$ core repeats (i.e. the minimal determinants of stable $\beta$-helical nanotube formation), polytheonamide BGCs have also been identified in the (meta)genomes of members from other bacterial phyla. ${ }^{[19]}$ Sources include another sponge metagenome (a gamma-proteobacterium), ${ }^{[20]}$ a single-cell genome representative of the Verrucomicrobia and the culturable beta-proteobacterium Microvirgula aerodenitrificans. Investigation of the latter pathway resulted in the characterization of aeronamide A, a cytotoxic polytheonamide congener featuring one dehydration, 21 alternating D-residues, five $N$-methylated Asn residues and seven $C$-methylations. ${ }^{[19]}$ In core-swapping experiments, $M$. aerodenitrificans also proved to be particularly efficient in generating hypermodified peptides, converting a core from the deep-rock biome to 'polygeonamides' that carry up to 23 D-amino acids. The studies have therefore also made a promising bacterial heterologous host available for the discovery of proteusins and biotechnological use of their diverse maturases.

\section{Landornamides}

Motivated by the remarkable diversity of peptide chemistries present in one single pathway in the polytheonamides, targeted bioinformatic searches of our group for additional proteusin pathways in bacterial genomes recently led to the characterization of landornamide A (Fig. 2B), ${ }^{[21]}$ a novel antiviral peptide from the cyanobacterium Kamptonema sp. PCC 6506. Despite featuring two installed D-configured residues installed by the rSAM epimerase OspD, landornamide A is markedly distinct from polytheonamide-type proteusins in that it bears two lanthionine rings rather than forming a $\beta$-helix, and features Orn residues as a novel PTM. This latter transformation is catalyzed by OspR, a new arginase-like enzyme that hydrolyzes two LArg residues to L-Orn in the OspA precursor peptide, producing urea as a side product. L-Orn and its derivatives occur among several important peptide antibiotics of non-ribosomal origin, including daptomycin and gramicidin $\mathrm{S}$, and are known to confer proteolytic stability on peptides. ${ }^{[22]}$ In subsequent work, OspR was found to belong to a larger family of peptide arginases from diverse organisms with diverse putative substrates. ${ }^{[23]}$ A subset of OspR homologs were tested for their bioengineering potential and were shown to be again highly promiscuous, even capable of modifying poly-Arg-repeat peptides. OspR homologs were also successfully applied to produce five Orn-containing pseudonon-ribosomal products, including an analog of the antibiotic brevicidine, further highlighting the utility of promiscuous RiPP maturases as biotechnological tools.

\section{Spliceotides}

As a final example of unprecedented peptide chemistry discovered by proteusin mining, we recently described a previously uncharacterized member of the rSAM enzyme superfamily that performs a remarkable peptide splicing transformation. ${ }^{[24]}$ The gene responsible was identified within the $p l p$ BGC from Pleurocapsa sp. PCC 7319, which encodes the previously characterized proteusin epimerase PlpD and its proteusin-type substrate PlpA1 (Fig. 2C). ${ }^{[14,15 a]}$ The splicing enzyme, PlpX, was shown to modify alternate substrates PlpA2 and PlpA3 encoded on the same BGC, which both bear $N$-terminal homology to Nif11, a protein putatively involved in nitrogen fixation. Like NHLP leaders, Nif11-type precursors are also widespread in RiPP BGCs across cyanobacteria. ${ }^{[25]}$ Co-expression and incorporation studies using isotopically labelled precursors revealed that PlpX targets 'XYG' motifs present within these two Nif11type substrates, and catalyzes the net excision of a tyramine equivalent from the peptide backbone (Fig. 2C). ${ }^{[24]}$ Bond formation between the remaining amide carbonyl of Tyr and the adjacent carbonyl results in the introduction of an $\alpha$-keto- $\beta$-amino moiety with a side chain derived from the upstream amino acid. This discovery represents a fundamental shift from textbook knowledge on natural ribosomal products, which is based exclusively on $\alpha$-amino acid backbone topology. Furthermore, the $\alpha$-ketoamide moiety is a known pharmacophore of natural nonribosomal and synthetic protease inhibitors, ${ }^{[26]}$ effecting inhibition via the reversible binding of nucleophilic Ser or Cys active site residues to the $\alpha$-keto group. PlpX was found to display significant tolerance for non-native substrates, allowing us to generate an engineered precursor to boceprevir, an approved $\alpha$-ketoamide drug for the treatment of chronic hepatitis $C$ infections. We were also able to tag the $\alpha$-ketoamide in vitro with the fluorogenic probe fluorescein thiosemicarbazine, further highlighting the potential of PlpX as a tool for introducing orthogonal reactions sites for further chemical diversification.

\section{Conclusions}

The RiPP class of NPs continues to expand rapidly, and yet, the extent of peptide chemical diversity locked away in uncharacterized RiPP biosynthetic pathways remains to be fully realized. ${ }^{[7,8,27]}$ Not only does the discovery of novel RiPPs expand the known chemistries from previously characterized families, but new RiPP families with their own novel defining PTMs continue to be discovered with remarkable frequency. ${ }^{[8]}$ RiPPs therefore represent one of the most promising sources of bioactive molecules and synthetic tools for peptide innovations. ${ }^{[28]}$ Our own investigations into the proteusin RiPP family have already uncovered an unexpected array of new maturases that install biologically relevant functionalities into peptides, despite only few representatives yet being known for this family. Given the abundance of uncharacterized proteusin-like and Nif11 BGCs encoded in bacterial genomes, ${ }^{[25]}$ and the fact that proteusins are not bound to family-defining peptide moieties, we are extremely excited for future discoveries that await us in the uncharted proteusin chemical space. Considering the ease with which core peptide sequences can be varied in the encoding genes, and the significant effects minor alterations can have on final product structure, the chemical space accessible by RiPP enzymes is seemingly limitless, a major boon for the field of peptide therapeutics. 


\section{Acknowledgements}

The authors are grateful for funding from the European Union (EU; SynPeptide 613981), the Swiss National Science Foundation (SNF; 407240_1167051,205321_165695,205320_185077,31003A_146992), and ETH Zurich (ETH-03 15-1). The authors would also like to thank Anna L. Vagstad and former lab members Cristian Gurgui, Michael F. Freeman, Brandon I. Morinaka, Maximilian J. Helf, Madlen Korneli, Sebastian W. Fuchs, Yohei Morishita, and Teigo Asai for their invaluable contributions.. Finally, we would also like to thank Muriel Gugger and Shigeki Matsunaga as important collaborators in this work.

Received: April 19, 2021

[1] M. Muttenthaler, G. F. King, D. J. Adams, P. F. Alewood, Nat. Rev. Drug Discov. 2021, https://doi.org/10.1038/s41573-020-00135-8.

[2] a) J. A. Hutchinson, S. Burholt, I. W. Hamley, J. Pept. Sci. 2017, 23, 82, https://doi.org/10.1002/psc.2954

b) M. R. Naylor, A. T. Bockus, M.-J. Blanco, R. S. Lokey, Curr. Opin. Chem. Biol. 2017, 38, 141, https://doi.org/10.1016/j.cbpa.2017.04.012; c) J. L. Lau, M. K. Dunn, Bioorg. Med. Chem. 2018, 26, 2700, https://doi.org/10.1016/j.bmc.2017.06.052.

[3] D. J. Newman, G. M. Cragg, J. Nat. Prod. 2020, 83, 770, https://doi.org/10.1021/acs.jnatprod.9b01285.

[4] R. D. Süssmuth, A. Mainz, Angew. Chem. Int. Ed. 2017, 56, 3770, https://doi.org/10.1002/anie.201609079.

[5] M. Bodanszky, D. Perlman, Nature 1964, 204, 840, https://doi.org/10.1038/204840a0.

[6] a) A. Hurst, J. Gen. Microbiol. 1966, 44, 209, https://doi.org/10.1099/00221287-44-2-209; b) L. Ingram, Biochim. Biophys. Acta 1970, 224, 203; c) L. M. Repka, J. R. Chekan, S. K. Nair, W. A. van der Donk, Chem. Rev. 2017, 117, 5457, https://doi.org/10.1021/acs.chemrev.6b00591

[7] P. G. Arnison, M. J. Bibb, G. Bierbaum, A. A. Bowers, T. S. Bugni, G. Bulaj, J. A. Camarero, D. J. Campopiano, G. L. Challis, J. Clardy, P. D. Cotter, D.J. Craik, M. Dawson, E. Dittmann, S. Donadio, P. C. Dorrestein, K.-D. Entian, M. A. Fischbach, J. S. Garavelli, U. Göransson, C. W. Gruber, D.H. Haft, T. K. Hemscheidt, C. Hertweck, C. Hill, A. R. Horswill, M. Jaspars, W. L. Kelly, J. P. Klinman, O. P. Kuipers, A. J. Link, W. Liu, M. A. Marahiel, D. A. Mitchell, G. N. Moll, B. S. Moore, R. Müller, S. K. Nair, I. F. Nes, G. E. Norris, B. M. Olivera, H. Onaka, M. L. Patchett, J. Piel, M. J. T. Reaney, S. Rebuffat, R. P. Ross, H.-G. Sahl, E. W. Schmidt, M. E. Selsted, K. Severinov, B. Shen, K. Sivonen, L. Smith, Torsten Stein, R. D. Süssmuth, J. R. Tagg, G.-L. Tang, A. W. Truman, J. C. Vederas, C. T. Walsh, J. D. Walton, S. C. Wenzel, J. M. Willey, W. A. van der Donk, Nat. Prod. Rep. 2013, 13, 108, https://doi.org/10.1039/C2NP20085F.

[8] M. Montalbán-López, T. A. Scott, S. Ramesh, I. R. Rahman, A. J. van Heel, J. H. Viel, V. Bandarian, E. Dittmann, O. Genilloud, Y. Goto, M. J. G. Burgos, C. Hill, S. Kim, J. Koehnke, J. A. Latham, A. J. Link, B. Martínez, S. K. Nair, Y. Nicolet, S. Rebuffat, H. -G. Sahl, D. Sareen, E. W. Schmidt, L. Schmitt, K. Severinov, R. D. Süssmuth, A. W. Truman, H. Wang, J.-K. Weng, G. P. van Wezel, Q. Zhang, J. Zhong, J. Piel, D. A. Mitchell, O. P. Kuipers, W. A. van der Donk, Nat. Prod. Rep. 2021, 38, 130 https://doi.org/10.1039/D0NP00027B.

[9] a) G. M. König, S. Kehraus, S. F. Seibert, A. Abdel-Lateff, D. Müller, ChemBioChem 2006, 7, 229, https://doi.org/10.1002/cbic.200500087; b) M. F. Mehbub, J. Lei, C. Franco, W. Zhang, Mar. Drugs 2014, 12, 4539, https://doi.org/10.3390/md12084539; c) A. R. Carroll, B. R. Copp, R. A. Davis, R. A. Keyzers, M. R. Prinsep, Nat. Prod. Rep. 2019, 36, 122, https://doi.org/10.1039/C8NP00092A.

[10] M. C. Wilson, T. Mori, C. Rückert, A. R. Uria, M. J. Helf, K. Takada, C. Gernert, U. A. E. Steffens, N. Heycke, S. Schmitt, C. Rinke, E. J. N. Helfrich, A. O. Brachmann, C. Gurgui, T. Wakimoto, M. Kracht, M. Crüsemann, U.
Hentschel, I. Abe, S. Matsunaga, J. Kalinowski, H. Takeyama, J. Piel, Nature 2014, 506, 58, https://doi.org/10.1038/nature12959.

[11] M. F. Freeman, C. Gurgui, M. J. Helf, A. R. Uria, N. J. Oldham, H.-G. Sahl, S. Matsunaga, J. Piel, Nature 2012, 338, 387, https://doi.org/10.1126/science.1226121.

[12] M. F. Freeman, M. J. Helf, A. Bhushan, B. I. Morinaka, J. Piel, Nat. Chem. 2017, 9, 387, https://doi.org/10.1038/nchem.2666.

[13] a) A. Parent, A. Benjdia, A. Guillot, X. Kubiak, C. Balty, B. Lefranc, J. Leprince, O. Berteau J. Am. Chem. Soc. 2018, 140, 2469, https://doi.org/10.1021/jacs.7b08402; b) A. L. Vagstad, T. Kuranaga, S Püntener, V. r. Pattabiraman, J. W. Bode, J. Piel, Angew. Chem. Int. Ed. 2019, 58, 2246, https://doi.org/10.1002/anie.201809508.

[14] B. I. Morinaka, M. Everest, M. F. Freeman, M. Gugger, J. Piel, Angew. Chem. Int. Ed. 2017, 56, 762, https://doi.org/10.1002/anie.201609469.

[15] a) B. I. Morinaka, A. L. Vagstad, M. J. Helf, M. Gugger, C. Keglr, M. F. Freeman, H. B. Bode, J. Piel, Angew. Chem. Int. Ed. 2014, 53, 8503, https://doi.org/10.1002/anie.201400478; b) S. W. Fuchs, G. Lackner, B. I. Morinaka, Y. Morishita, T. Asai, S. Riniker, J. Piel, Angew. Chem. Int. Ed. 2016, 55, 12330, https://doi.org/10.1002/anie.201602863.

[16] M. Korneli, S. W. Fuchs, K. Felder, C. Ernst, L. V. Zinsli, J. Piel, ACS Synth. Biol. 2021, 10, 236, https://doi.org/10.1021/acssynbio.0c00470.

[17] A. Renevey, S. Riniker, Eur. Biophys. J. 2017, 46, 363, https://doi.org/10.1007/s00249-016-1179-1.

[18] a) N. Shinohara, H. Itoh, S. Matsuoka, M. Inoue, ChemMedChem 2012, 7, 1770, https://doi.org/10.1002/cmdc.201200142; b) A. Hyata, H. Itoh, S. Matsutaka, M. Inoue, Chem. Eur. J. 2016, 22, 3370, https://doi.org/10.1002/chem.201504632; c) M. F. Freeman, A. L. Vagstad, J. Piel, Curr. Opin. Chem. Biol. 2016, 31, 8, https://doi.org/10.1016/j.cbpa.2015.11.002.

[19] A. Bhushan, P. J. Egli, E. E. Peters, M. F. Freeman, J. Piel, Nat. Chem. 2019 11, 931, https://doi.org/10.1038/s41557-019-0323-9.

[20] M. Rust, E. J. N. Helfrich, M. F. Freeman, P. Nanudorna, C. M Field, C. Rückert, T. Kündig, M. J. Page, V. L. Webb, J. Kalinowski, S. Sunagawa, J. Piel, Proc. Natl. Acad. Sci. USA 2020, 117, 9508, https://doi.org/10.1073/pnas.1919245117.

[21] N. M. Bösch, M. Borsa, U. Greczmiel, B. I. Morinaka, M. Gugger, A. Oxenius, A. L. Vagstad, J. Piel, Angew. Chem. Int. Ed. 2020, 59, 11763 , https://doi.org/10.1002/anie.201916321.

[22] a) R. Böttger, R. Hoffmann, D. Knappe, PLoS One 2017, 12, e0178943, https://doi.org/10.1371/journal.pone.0178943; b) M. Arias, K. B. Piga, M. E. Hyndman, H. J. Vogel, Biomolecules 2018, 8, 19, https://doi.org/10.3390/biom8020019.

[23] S. Mordhorst, B. I. Morinaka, A. L. Vagstad, J. Piel, Angew. Chem. Int. Ed. 2020, 59, 21442, https://doi.org/10.1002/anie.202008990.

[24] B. I. Morinaka, E. Lakis, M. Everest, M. J. Helf, T. Scalvenzi, A. L. Vagstad, J. Sims, S. Sunagawa, M. Gugger, J. Piel, Science 2018, 359, 779, https://doi.org/10.1126/science.aao0157.

[25] D. H. Haft, M. K. Basu, D. A. Mitchell, BMC Biol. 2010, 8, 70, https://doi.org/10.1186/1741-7007-8-70.

[26] C. De Risi, G. P. Pollini, V. Zanirato, Chem. Rev. 2016, 116, 3241, https://doi.org/10.1021/acs.chemrev.5b00443.

[27] T. A. Scott, J. Piel, Nat. Rev. Chem. 2019, 3, 404, https://doi.org/10.1038/s41570-019-0107-1.

[28] T. Dang, R. D. Süssmuth, Acc. Chem. Res. 2017, 50, 7, https://doi.org/10.1021/acs.accounts.7b00159.

\section{License and Terms}

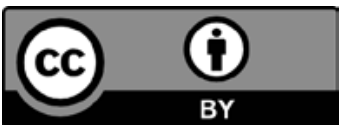

This is an Open Access article under the terms of the Creative Commons Attribution License CC BY 4.0. The material may not be used for commercial purposes.

The license is subject to the CHIMIA terms and conditions: (http:// chimia.ch/component/sppagebuilder/?view=page \&id=12).

The definitive version of this article is the electronic one that can be found at https://doi.org/10.2533/chimia.2021.543 